\title{
A expansão do mercado de educação superior privada no Brasil e a falta de marco econômico regulatório
}

O setor privado de educação superior brasileira atingiu, em 2013 , o faturamento de $\mathrm{R} \$ 32 \mathrm{bi}$ apenas na graduação. A concentração da educação superior brasileira é constatada através da consolidação de grandes grupos, os quais pode ser verificado através dos atos publicados pelo CADE (Conselho Administrativo de Desenvolvimento Econômico). $\mathrm{O}$ grau de complexidade destes atos também se intensificou nos últimos anos. Este artigo tem como objetivo analisar os atos de concentração e a regulação existente no mercado brasileiro de educação superior privado.

Palavras-chave: Educação superior privada; Regulação; Plano Nacional de Educação.

\section{The expansion of the private higher education market in Brazil and the lack of regulatory economic framework}

The Brazilian private higher education sector reached, in 2013 , revenues of $R \$ 32 \mathrm{bi}$ only in undergraduate studies. The concentration of Brazilian higher education is evidenced by the consolidation of large groups, which can be verified through the acts published by CADE (Administrative Council of Economic Development). The degree of complexity of these acts has also intensified in recent years. This article aims to analyze the acts of concentration and regulation existing in the Brazilian private higher education market.

Keywords: Private higher education; Regulation; National Education Plan.

Topic: Políticas Públicas na Educação

Reviewed anonymously in the process of blind peer

Alexsandro da Silva

Universidade do Sul de Santa Catarina, Brasil

http://lattes.cnpq.br/9142330909980362

alexsandro.silva2@unisul.br

d

DOI: 10.6008/SPC2318-3047.2017.001.0001
Received: 24/02/2017

Approved: 21/06/2017
Referencing this:

SILVA, A.. A expansão do mercado de educação superior privada no Brasil e a falta de marco econômico regulatório. Educationis, v.5, n.1, p.6-13, 2017. DOI: http://doi.org/10.6008/SPC23183047.2017.001.0001 


\section{INTRODUÇÃO}

O Plano Nacional de Educação - PNE (2014/2024), tem as seguintes metas para a educação superior: a elevação da taxa de escolarização bruta de matrícula para 50\% da taxa líquida para 33\% e da população de 18 (dezoito) a 24 (vinte e quatro) anos em 2024. O governo brasileiro, buscando atingir os percentuais legalmente destacados no PNE para 2024, considerou os patamares de 2013 (30\% para a taxa bruta e 20\% para a taxa líquida). Para isso, houve a necessidade de transformações, especificamente, no mercado de educação superior privado brasileiro. Tais atitudes podem ser constatadas pelo intenso processo de fusões e aquisições neste setor e a grande expansão da educação à distância. Há de se destacar, também, as políticas públicas de ampliação do acesso à educação superior, tanto na rede pública, como na rede privada.

A educação superior brasileira expressa-se por um grande e expressivo número de matrículas. Porém, os percentuais da população brasileira com formação superior ainda são bem menores que as nações da América Latina e da Organização para a Cooperação e Desenvolvimento Econômico (OCDE). Em 2012, quando se registrava um percentual da população adulta (25 a 64 anos) com educação superior média, nos países da Organização para a Cooperação e Desenvolvimento Econômico (OCDE) era pouco maior que 32\%. No Brasil, tais percentuais não atingiam $13 \%$ da população.

Mesmo com os esforços do governo brasileiro para desenvolver políticas para ampliar as ofertas de vagas e proporcionar mecanismos de permanência dos alunos nas instituições públicas por meio de programas, tais como o REUNI (Programa de Apoio a Planos de Reestruturação e Expansão das Universidades Federais), também foram desenvolvidas políticas como PROUNI (Programa Universidade para todos), FIES (Financiamento Eestudantil), PROIES (Programa de Estímulo à Reestruturação e ao Fortalecimento das Instituições de Ensino Superior), dentre outras implementadas com o mesmo intuito na educação superior privada.

A educação superior tem abrangência aos cursos sequenciais, de graduação (bacharelado, licenciatura), de pós-graduação (stricto e lato sensu) e de extensão. O governo brasileiro, através da Lei de Diretrizes e Bases da Educação Nacional - LDB (Lei 9.394/1996) define esta abrangência e o Censo da Educação Superior, divulgado anualmente, e apresenta os dados oficiais para este nível de ensino com informações de estoque (número de matrículas e de cursos, por exemplo), assim como de fluxo (número de ingressantes e concluintes).

\begin{tabular}{|c|c|c|c|c|c|c|}
\hline \multirow{3}{*}{$\begin{array}{l}\text { Estatísticas } \\
\text { Băsicas }\end{array}$} & \multicolumn{6}{|c|}{ Categoria Administrativa } \\
\hline & \multirow[b]{2}{*}{ Total Geral } & \multicolumn{4}{|c|}{ Pública } & \multirow[b]{2}{*}{ Privado } \\
\hline & & Total & Federal & Estadual & Municipal & \\
\hline $\begin{array}{l}\text { Número de } \\
\text { Instituiçōes }\end{array}$ & 2391 & 301 & 106 & 119 & 76 & 2090 \\
\hline \multicolumn{7}{|c|}{ Educação Superior - Graduação } \\
\hline Cursos & 32.049 & 10.850 & 5.968 & 3.656 & 1.226 & 21.199 \\
\hline Matricula & 7.305 .977 & 1.932 .527 & 1.137 .851 & 604.517 & 190.159 & 5.373 .450 \\
\hline $\begin{array}{l}\text { Ingresso } \\
\text { Total }\end{array}$ & 2.742 .950 & 531.846 & 325.267 & 142.842 & 63.737 & 2.211 .104 \\
\hline Concluintes & 991.010 & 229.278 & 115.336 & 82.892 & 31.050 & 761.732 \\
\hline \multicolumn{7}{|c|}{ Educação Superior - Sequencial de Formação Específica } \\
\hline Matriculas & 16.987 & 489 & 100 & 208 & 181 & 16.498 \\
\hline \multicolumn{7}{|c|}{ Educação Superior - Pós Graduação Strictu Sensu } \\
\hline Matrículas & 203.717 & 172.026 & 115.001 & 56.094 & 931 & 31.691 \\
\hline \multicolumn{7}{|c|}{ EDUCACÃO SUPERIOR - TOTAL } \\
\hline $\begin{array}{l}\text { Matricula } \\
\text { Total }\end{array}$ & 7.526 .681 & 2.105 .042 & 1.252 .952 & 660.819 & 191.271 & 5.421 .639 \\
\hline
\end{tabular}

Tabela 1: estatísticas gerais da educação superior brasileira em 2013. Fonte: MEC. 
Constata-se, conforme a tabela apresentada, que mais de $70 \%$ das matrículas na educação superior se concentram no setor privado, e que o número de instituições superiores privadas supera em quase 7 (sete) vezes superior o número de instituições públicas. A educação superior pode, também, ser ofertada nas modalidades presencial e à distância. Ao se restringir às matrículas em cursos de graduação na modalidade à distância, o percentual chega a $86 \%$ no setor privado, como podemos verificar na Tabela 2. No entanto, há de se destacar que o percentual de matrículas na modalidade a distância acresceu de 1,2\% em 2003 para quase $16 \%$ do total de matrículas de graduação, destacados a seguir.

\begin{tabular}{|c|c|c|c|c|}
\hline \multirow[t]{2}{*}{ Ano } & \multirow{2}{*}{$\begin{array}{c}\text { Categoria } \\
\text { Administrativa }\end{array}$} & \multicolumn{3}{|c|}{ Matrículas em Curso de Graduação } \\
\hline & & Total & Presencial & A distância \\
\hline \multirow[t]{5}{*}{2003} & Total & 3.936 .933 & 3.887 .022 & 49.911 \\
\hline & Federal & 583.633 & 567.101 & 16.532 \\
\hline & Estadual & 465.978 & 442.706 & 23.272 \\
\hline & Municipal & 126.563 & 126.563 & - \\
\hline & Privada & 2.760 .759 & 2.750 .652 & 10.107 \\
\hline \multirow[t]{5}{*}{2013} & Total & 7.305.977 & 6.152 .405 & 1.153 .572 \\
\hline & Federal & 1.137 .851 & 1.045 .507 & 92.344 \\
\hline & Estadual & 604.517 & 557.588 & 46.929 \\
\hline & Municipal & 190.159 & 174.879 & 15.280 \\
\hline & Privada & 5.373 .450 & 4.374 .431 & 999.019 \\
\hline
\end{tabular}

Tabela 2: número de matrículas em cursos de graduação por modalidade de ensino. Fonte: MEC.

O crescimento no número de matrículas da educação superior brasileira no período referente aos anos de 2003 e 2013, 3,3 milhões de matrículas foram registradas nos cursos de educação à distância. Dessa forma, o acréscimo nas matrículas sustenta-se pelo aumento substancial da modalidade à distância, que atingiu em 2013 impressionantes 16\% das matrículas.

Neste comparativo, o expansionismo da educação superior teve seu crescimento consolidado pelo setor privado como maior ofertante de matrículas e, ainda pelo intenso processo de fusões e aquisições no setor privado, marcado pelo surgimento de grandes grupos econômicos no mercado de educação superior privado brasileiro. No ano de 2013, apenas na graduação, o setor privado da educação, obteve o faturamento de $R \$ 32 b i$.

Marcado pelo processo de intensificação da concentração no mercado de educação superior, profundas alterações no perfil das mantenedoras das instituições privadas ocorreram a partir da década de 1990, que ocasionou um intenso processo de fusões e de profissionalização da gestão destas instituições. Os grupos econômicos, mantenedores das instituições superiores privadas brasileiras, classificam-se como as de capital aberto e a de capital estrangeiro. Classificadas como no primeiro grupo, tem-se: Kroton/Anhanguera, Estácio, Anima Educação (GAEC) e Ser Educacional; e no segundo grupo, Laureate e Devry. Os grupos Uninove, Unicsul, Whitney e Grupo Tiradentes - UNIT, além de se destacarem por possuírem maiores participações de mercado, tanto em receita quanto em número de matrículas, não há como configurá-las como grupos econômicos em toda essência, pois congregam uma ou, no máximo, duas instituições de educação superior.

Nesta caracterização, temos a Whitney que possui duas IES no Brasil: Universidade Veiga de Almeida - UVA, localizada no Rio de Janeiro, e o Centro Universitário Jorge Amado - UniJorge, situado na Bahia. 
A Unip/Holding Di Gênio é outro caso extremamente peculiar. Conforme descreveu a reportagem da revista EXAME, como o maior império de educação superior de capital fechado do país. Citando os 27 campi da Unip, mais 28 faculdades de outras marcas e 598 polos de ensino à distância segundo, a reportagem. 0 referido grupo possui como mantenedoras principais a ASSUPERO (Associação Unificada Paulista de Ensino Renovado Objetivo) e a ASSOBES (Associação Objetivo de Ensino Superior).

\section{METODOLOGIA}

Os procedimentos metodológicos utilizados foram a pesquisa bibliográfica, por meio de livros e artigos, que proporcionaram uma revisão da literatura sobre o tema. Foram utilizados outros tipos de pesquisas também, como a qualitativa e exploratória. A abordagem do problema se estabeleceu por meio de uma pesquisa qualitativa, sendo que Michel (2015) pontua que a verdade sobre os fatos, não se comprova por meios numéricos ou estatísticos, mas sim por meio da análise detalhada abrangente e na argumentação das ideias apresentadas, sendo que tem como objetivo explorar as opiniões e diferenças sobre o assunto estudado.

O objetivo da pesquisa se pôs de cunho exploratório, que de acordo com Andrade (2005), é aquela que constitui uma iniciação do tema que irá se pesquisar, com isso, obtendo maiores informações sobre o assunto, assim contribuindo para a divulgação do mesmo como algo novo, ou até uma continuação do respectivo tema. Já na visão de Santos (2004), a pesquisa exploratória consiste na familiarização do tema em questão, e consequentemente no aprofundamento do conhecimento sobre o mesmo; assim o pesquisador buscará por meio de informações já disponíveis nas fontes de informações, como: livros, revistas, artigos, websites, os dados que fundamentarão a escrita, sendo que esse tipo de pesquisa é quase sempre feito na forma de levantamento bibliográfico. Esse consiste em um arcabouço de materiais escritos a respeito do tema pesquisado.

\section{REVISÃO TEÓRICA}

\section{As mantenedoras de capital aberto}

Em 2007 ocorreram as primeiras aberturas de capital (IPOs) na bolsa de valores no mercado de educação superior. A IPO da Anhanguera Educacional ocorreu no mês de março, e as da Kroton Educacional e a da Estácio ocorreram no mês de julho. Em outubro de 2013, Ser Educacional e a Anima Educacional realizaram abertura de capital na bolsa de valores. O objetivo explícito de captação de recursos para expansão dos grupos por meio de aquisição de IES é comum a todos estes processos de abertura de capital. Destaca-se também como motivo para o sucesso da abertura de capital, a grande demanda por educação superior no Brasil e o incentivo governamental, via FIES e PROUNI, para a ampliação da base de alunos na rede privada.

A Estácio, fundada em 1970, após a abertura de capital em 2007, iniciou um intenso processo de expansão que permitiu sua atuação em todos os estados brasileiros. Em 2012, chegou ao Amapá, Maranhão, 
Paraíba e Rio Grande do Sul e, em 2013, ampliou a oferta de EaD, e consolidou presença em São Paulo com a aquisição da UniSeb, chegando ainda ao Distrito Federal e realizando mais uma aquisição em Santa Catarina, a Assesc.

O grupo Anima, instituído em 2003, é composto por cinco IES: os Centros Universitários UNA e UniBH, em Belo Horizonte; Monte Serrat (Unimonte), em Santos; a HSM Educação Executiva, em São Paulo, adquirida em 2013; e a Universidade São Judas Tadeu (USJT), em São Paulo, adquirida em abril de 2014. A aquisição da USJT demonstra um aumento significativo no número de matrículas do grupo, saltando de 49.000 matrículas para mais de 80.000 matrículas.

O grupo Ser Educacional possui 22 (vinte e duas) IES nas regiões Norte e Nordeste do país. Em outubro de 2014, adquiriu União de Ensino Superior do Pará, mantenedora da Universidade da Amazônia, e do Instituto Santareno de Educação Superior, mantenedor das Faculdades Integradas Tapajós. Em 2015, o grupo iniciou processo de expansão na região Sudeste, com a aquisição da Universidade Guarulhos - UnG e do Centro Universitário Bennet, no Rio de Janeiro.

\section{Mantenedoras de instituições de ensino superior brasileiro de capital estrangeiro}

Em 2009, a rede estadunidense de ensino Devry Internacional iniciou seus investimentos no mercado brasileiro por meio da aquisição do Grupo Fanor, no Nordeste. A DeVry possui instituições de ensino superior nas regiões Norte e Nordeste, tendo aumentado significativamente seus avanços em investimentos. Em dezembro de 2014, adquiriu o grupo Damásio Educacional, com atuação em cursos de graduação e pósgraduação na área de Direito em São Paulo, além do ensino à distância em todo o Brasil.

Grupo estadunidense Laureate Internacional adquiriu, em 2005, o controle da Universidade Anhembi Morumbi, iniciando seus investimentos no mercado brasileiro. O grupo compõe-se por doze instituições de ensino superior possuindo mais de cinquenta campi em oito estados brasileiros. Fazem também parte da rede Laureate Brasil:

BSP - Business School São Paulo;

CEDEPE Business School;

Centro Universitário das Faculdades Metropolitanas Unidas - FMU;

Centro Universitário do Norte (UniNorte);

Centro Universitário IBMR;

Centro Universitário Ritter dos Reis (UniRitter);

Faculdade de Desenvolvimento do Rio Grande do Sul (FADERGS);

Faculdade dos Guararapes (FG);

Faculdade Internacional da Paraíba (FPB);

Universidade Anhembi Morumbi; Universidade Potiguar (UnP); e

Universidade Salvador (UNIFACS). 


\section{O Estado e o controle do ensino superior}

O Estado possui uma relevante importância quanto à educação superior, tanto no credenciamento de instituições, quanto na garantia de qualidade dos cursos ou na indução de oferta de formação de profissionais para um dado setor econômico. Há de destacar, ainda, o papel do Estado em estabelecer critérios de avaliação de cursos e das instituições de forma a fornecer à sociedade informações sobre a qualidade dos cursos oferecidos.

O Estado, como forma de disponibilizar ferramentas de consulta sobre as Instituições de Educação Superior, criou, no ano de 2002, o Sistema de Informações Educacionais do Ensino Superior - SIEdSup. O eMEC, sistema eletrônico de operacionalização dos procedimentos de regulação, foi instituído em 2007, permitindo o acesso do público a dados referente a situação de regulação das instituições, como também dos cursos por elas oferecidos, endereços de oferta e indicadores de qualidade obtidos nas avaliações do MEC.

Com a perspectiva de um crescimento agregado, a meta de investimento de $10 \%$ do PIB na educação, prevista no PNE, faz com que o Estado realize, na educação superior, uma regulação mais efetiva, proporcionando à sociedade informações confiáveis a respeito dos cursos de educação superior oferecidos, possibilitando um aumento do percentual da população com educação superior, trazendo uma grande contribuição à economia.

As contribuições ou os benefícios proporcionados pela educação superior fornecem ao indivíduo benefícios de cunhos privados e pessoais, além de um aumento produtivo em seu ambiente de trabalho. Também a regulação do mercado do ensino superior se faz ainda mais necessária, em se tratando da qualidade da mão de obra disponibilizada pelos cursos de educação superior, apesar de profissionais envolvidos com a educação superior significante. Há de se destacar que, em países desenvolvidos, marcados pelo desenvolvimento científico, tem um elevado percentual da população com educação superior.

A necessidade da regulação tem, ainda, uma função importante, que é de proteger o estude no caso de falência de instituições de ensino superior, assim como as que ocorreram com a Universidade Gama Filho e da UniverCidade, ambas no Rio de Janeiro, que tiveram um grande impacto negativo para milhares de estudantes. Já era de conhecimento que ambas as instituições passavam por dificuldades financeiras em virtude da má gestão, tendo sido transferidas em 2012 para a mantenedora Galileo. Ainda assim, as dificuldades econômico-financeiras se mantiveram e, consequentemente, recaindo a qualidade acadêmica, vindo o MEC descredenciar as duas instituições em janeiro de 2014.

\section{O quase-mercado de educação superior}

O interesse econômico pela oferta de educação superior no Brasil é fato relevante, como também a necessidade da participação do setor privado para o alcance da política de expansão prevista no Plano Nacional de Educação. Faz-se necessária a participação do setor privado, em virtude da insuficiência de recursos estatais para o fornecimento de educação superior a demanda existente. 
O governo brasileiro, através de políticas, como o PROUNI e o FIES incentivam a ampliação destas ofertas de vagas em cursos de graduação por meio de investimentos estatais às instituições de ensino superior privadas. Com a utilização da política do PROUNI, o objetivo é disponibilizar bolsas de estudo integrais e parciais, podendo ser tanto em cursos presenciais quanto à distância em instituição de ensino superior privadas; porém, o FIES é um programa de financiamento exclusivo a cursos de educação superior presenciais, e com juros subsidiados pelo Estado. Mészáros (2007) destaca que:

Poucos negariam hoje que a educação e os processos de reprodução mais amplos estão intimamente ligados. Consequentemente, uma reformulação significativa da educação é inconcebível sem a correspondente transformação do quadro social no qual as práticas educacionais da sociedade devem realizar as suas vitais e historicamente importantes funções de mudança. Mas para além do acordo sobre este simples fato os caminhos dividem-se severamente. Pois, caso um determinado modo de reprodução da sociedade seja ele próprio tido como garantido, como o necessário quadro de intercâmbio social, nesse caso apenas são admitidos alguns ajustamentos menores em todos os domínios em nome da reforma, incluindo o da educação. As mudanças sob tais limitações conjecturais e apriorísticas são admissíveis apenas com o único e legitimo objetivo de corrigir algum detalhe defeituoso da ordem estabelecida, de forma a manter-se as determinações estruturais fundamentais da sociedade como um todo intactas, em conformidade com as exigências inalteráveis de um sistema reprodutivo na sua totalidade lógico.

É necessária uma intensa regulação do mercado de educação superior no brasil, tendo em vista que, ainda, o Estado brasileiro manter a educação superior via instituição de ensino superior públicas, o estado ainda financia $44 \%$ das matrículas das instituições de ensino privadas. Havendo a necessidade do estado regulador.

\section{As instituições de ensino superior privada e o aumento progressivo das fusões e aquisições no mercado de educação superior privado}

As instituições de ensino superior privado brasileiro são classificadas como sendo particulares em sentido estrito, comunitárias, confessionais e filantrópicas. Entretanto, estas se dividem em dois grandes grupos, podendo ser instituições de ensino superior privadas com finalidade lucrativa, as quais não se caracterizam como sendo particulares em sentido estrito, e as instituições de ensino superior privadas sem fim lucrativo, que possuem suas características caracterizadas como comunitárias, confessionais e filantrópicas. Chaves (2010) referencia:

Por fim, deve-se registrar que o crescimento desse setor aprofunda as tendências de transformação da educação num grande "negócio" a ser comercializado no mercado capitalista e de constituição dos estudantes em clientes-consumidores, "disputados por instituições privadas de ensino superior que reproduzem, em seu interior, relações capitalistas, por meio de práticas instrumentais e utilitaristas, distanciando-se da reflexão crítica e da educação como possibilidade emancipadora".

Em virtude da alteração das instituiç̧̃̃es educacionais superiores para um modelo com determinada finalidade, possibilitou-as assumirem em sua constituição, as formas admitidas em direito, tanto em natureza civil, quanto comercial. 


\section{CONCLUSÕES}

Foi possível, a partir do exposto, analisar a necessidade de o Estado ter definido o papel de cada instituição de ensino superior pública, privada com fins lucrativos, ou privada sem fins lucrativos, e adequar os fluxos de avaliação, supervisão e regulação. Há a necessidade de um aprimoramento na concessão estatal de permissão para funcionamento de cursos e instituições de educação superior, possibilitando, assim, maior agilidade e transparência nos atos autorizativos para funcionamento destes.

O sistema legal regulatório estatal deve adequar-se ao surgimento de grandes grupos econômicos neste setor, podendo ser capaz de limitar os prejuízos decorrentes desta concentração. Por fim, independente de como ocorra a oferta de educação superior, é fato que ela é extremamente necessária para o desenvolvimento do país. É papel do Estado garantir que toda instituição de ensino superior credenciada, seja ela pública, privada com fins lucrativos, ou privada sem fins lucrativos, oferte cursos com qualidade e aptos a formar cidadãos e profissionais de que o país necessita.

Características próprias de nosso sistema de educação superior exigem uma definição clara por parte do Estado, seja em sua atuação por meio da política de defesa da concorrência ou da regulatória. Conclui-se, portanto, que ao analisar a educação superior privada por meio de atos de concentração submetidos à autoridade antitruste brasileira e da regulação existente, observa-se que ao passo que o mercado de educação superior privado brasileiro se transforma, são exigidas do Estado melhorias na regulação da educação superior. Portanto, é necessário implementar muitas modificações na atuação estatal no mercado do ensino superior, que poderão se reverter em futuras melhorias no intuito de mitigar a assimetria de informação inerente a este mercado e, permitir que as metas estabelecidas pelo PNE sejam plenamente atingidas.

\section{REFERÊNCIAS}

CHAVES, V. L. J. Expansão da privatização/mercantilização do ensino superior brasileiro: a formação dos oligopólios. Educação \& Sociedade, Campinas, v.31, 2010.

MÉSZÁROS, I.. A educação para além do capital. Revista Theomai, Porto Alegre, n.15, 2007.
SGUISSARDI, V.. Educação superior no limiar do novo século: traços internacionais e marcas domésticas. Revista Diálogo Educacional. Curitiba, n.3, (2002). 